\title{
Evaluación del alcance de las reparaciones impuestas por la Corte Interamericana de Derechos Humanos contra Perú ${ }^{1}$
}

https://doi.org/10.21830/9789585287884.06

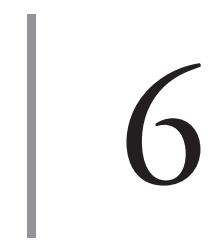

\author{
Manuel Bermúdez-Tapia ${ }^{2}$ \\ Universidad Privada San Juan Bautista \\ Paola Alexandra Sierra-Zamora ${ }^{3}$ \\ Escuela de Aviación del Ejército \\ Andrés Hernando Parra Espitia ${ }^{4}$ \\ Centro de Misiones Internacionales y Acción Integral
}

\section{Resumen}

Este capítulo analiza el alcance de las decisiones de la Corte Interamericana de Derechos Humanos (Corte IDH) en casos seguidos contra Perú, las cuales establecieron un diálogo entre las jurisdicciones que provocó la modificación de la legislación penal peruana, especialmente la vinculada a la lucha contra el terrorismo. El objetivo del estudio es evaluar la casuística jurisprudencial contra Perú en el ámbito del desarrollo del derecho convencional, para lo cual se realiza un estudio analítico y descriptivo de tipo cualitativo. De este modo, el análisis de casuística permite detallar el método mediante el cual se determinan las reparaciones a los Estados sancio-

1 Este capítulo forma parte de los resultados de los proyectos de investigación: "Perspectivas en Derechos Humanos y Derecho Internacional Humanitario para el Ejército Nacional de Colombia”, del grupo de investigación en Aviación Militar de la Escuela de Aviación del Ejército, registrado con el código COL0077618 y categorizado en $\mathrm{C}$ por Minciencias, y "Radiodifusión y sensibilización a través de las TIC: Memoria histórica y promoción de atención de víctimas del Conflicto Armado Interno”, del Grupo de Investigación del Centro de Misiones Internacionales, Acción Integral y Derechos Humanos (CEMAI). Los puntos de vista pertenecen a los autores y no reflejan necesariamente los de las instituciones participantes.

2 Abogado de la Pontificia Universidad Católica del Perú. Magíster en Derecho y doctorado en Derecho por la Pontificia Universidad Católica de Argentina. Profesor investigador de la Universidad Privada San Juan Bautista y profesor de la Facultad de Derecho de la Universidad Nacional Mayor de San Marcos, Lima, Perú. ORCID: https://orcid.org/0000-0003-1576-9464. Contacto: manuel.bermudez@upsjb.edu.pe

3 Abogada de la Universidad Católica de Colombia. Magíster en Derechos Humanos, Democracia y Justicia Internacional de la Universitat de València, España. Doctorado (en curso) del Programa de Derechos Humanos, Democracia y Justicia Internacional de la Universitat de València, Espańa. Investigadora de la Escuela de Aviación del Ejército, Bogotá, D. C., Colombia. ORCID: https:/orcid.org/0000-0002-3146-7418. Contacto: paolasierrazamora@cedoc.edu.co

4 Coronel del Ejército Nacional de Colombia. Especialista en Seguridad y Defensa Nacional de la Escuela Superior de Guerra "General Rafael Reyes Prieto". Profesional en Ciencias Militares de la Escuela Militar de Cadetes "General José María Córdova”. Director del Centro de Misiones Internacionales y Acción Integral del Ejército Nacional de Colombia, Bogotá, D. C., Colombia. 
nados, los cuales constituyen un elemento vinculante en el ámbito del Sistema Interamericano de Derechos Humanos.

Palabras clave: derecho convencional; diálogo entre jurisdicciones; jurisdicción nacional; jurisdicción supranacional; protección de los Derechos Humanos.

\section{Introducción}

En el ámbito del desarrollo de la práctica jurisdiccional en Perú se observa que los elementos básicos que regulan todo el procedimiento coercitivo y punitivo del Estado no están relacionados con el procedimiento que establece la Corte Interamericana de Derechos Humanos (Corte IDH) en sus decisiones, en particular respecto del alcance de las "reparaciones" a favor de las víctimas que han sufrido algún perjuicio en sus derechos o intereses.

Esta situación respondió principalmente al hecho de que durante la década de los años noventa del siglo pasado el poder judicial y el tribunal constitucional peruano habían sido maniatados por el poder político del entonces gobierno de Alberto Fujimori. Por lo tanto, ante la falta de tutela de los principales Derechos Humanos — vida, tutela jurisdiccional efectiva, libertad, entre otros - se tuvo que recurrir a la jurisdicción supranacional.

Consecuentemente, se generó una serie de reacciones que han incidido no solo en el ámbito judicial peruano, sino también en todo el continente, especialmente porque se ha modificado el alcance tuitivo de las normas internacionales de protección de derechos, la Convención Americana y el alcance progresivo, interdependiente, inalienable, imprescriptible, indivisible y universal de los Derechos Humanos.

De esta manera, surge un derecho convencional que permite delimitar el alcance de las diferentes especialidades en el ámbito jurídico nacional, especialmente en los países donde era desarrollado en forma desproporcional al usual ius imperium que les compete a las administraciones públicas. De este modo, el proceso de constitucionalización que ya se generaba se complementó con un proceso de convencionalidad, que permite estructurar una mejor comprensión de los alcances del derecho penal y del derecho procesal penal.

Producto de este diálogo entre órganos judiciales, el Sistema Interamericano de Derechos Humanos se ha desarrollado de tal modo que ha optimizado el control del poder, especialmente en aquellos ámbitos nacionales en donde los conceptos de democracia, gobernabilidad y diálogo entre el Estado y la población se habían condicionado negativamente. Las decisiones de la Corte Interamericana de 
Derechos Humanos en este ámbito desarrollaron nuevos contenidos, determinaron nuevos derechos y autonomizaron algunos patrones conceptuales que provocaron el surgimiento de nuevas condiciones y derechos específicos: por ejemplo, en el ámbito laboral se determinó la autonomía entre el derecho a acceder a una pensión de jubilación y el derecho al trabajo, conforme se detalla en el caso Cinco Pensionistas contra Perú. Igualmente, se hizo tangible el derecho a la verdad a favor de los deudos de las víctimas del gobierno de Alberto Fujimori-Vladimiro Montesinos, conforme se detalló en los casos Barrios Altos y La Cantuta.

Por ello, el análisis de las decisiones tiene un alcance superlativo y permite incidir en un aspecto puntual: el modo de determinar el alcance de las reparaciones, especialmente porque ello involucrará un alcance mucho más específico en el diálogo judicial entre la Corte Interamericana de Derechos Humanos con cada órgano judicial nacional en la región latinoamericana.

Esta situación permitirá además entender un poco el procedimiento general en el cual se desarrollan casos ante el Sistema Interamericano de Protección de Derechos Humanos, que incluye a la Corte IDH y a la Comisión Interamericana de Derechos Humanos (CIDH), por parte de un ciudadano que alega una afectación a sus derechos y que no cuenta con un nivel de tutela en su propio país como consecuencia de la inacción del poder judicial y del tribunal constitucional, si resulta vinculante en el ámbito de los ejercicios del ciudadano.

De esta manera, algunos principios constitucionales en el ámbito procesal y jurisdiccional vinculados a la tutela de derechos fundamentales, como la "tutela jurisdiccional efectiva", el "debido proceso", la "presunción de inocencia”, el "poder y norma punitiva como última ratio por parte del Estado" o el "plazo razonable", forman parte de las premisas que durante los últimos años han sido materia de evaluación en el derecho convencional, que no se limita al alcance teórico de la decisión por cuanto el trámite para su cumplimiento deberá ser también evaluado.

De este modo, es necesario abordar un aspecto final en el ámbito del procedimiento jurisdiccional que se sigue ante el Sistema Interamericano de Protección de los Derechos Humanos, el cual permite evaluar el modo en el que los órganos estatales nacionales deberán ejecutar una decisión que involucrará:

a. La evaluación de una normatividad que ha sido cuestionada y genera una evaluación negativa en el ámbito de la aplicabilidad de la Convención Americana, con lo cual se produce una "inconvencionalidad".

b. La evaluación de las acciones del Estado infractor, respecto de los hechos evaluados tanto por parte de la Comisión Interamericana 
de Derechos Humanos como por parte de la Corte Interamericana de Derechos Humanos.

c. Las acciones que deberá cumplir un Estado respecto del alcance de la decisión de la Corte Interamericana, que puede conllevar actos específicos, como también actos de carácter simbólico.

Por ello permítanos desarrollar el presente texto, que se centra en la parte impositiva y ejecutiva de las decisiones de la Corte Interamericana de Derechos Humanos, pero que a la par analiza en forma general algunos aspectos que determinan el contexto del seguimiento procedimental de un caso ante la jurisdicción de la Corte Interamericana de Derechos Humanos.

\section{El Sistema Interamericano de Protección de Derechos Humanos}

Es el sistema integrado a nivel jurisdiccional que existe en el ámbito de la Organización de los Estados Americanos (OEA) y que goza de una autonomía funcional y jurisdiccional frente a los Estados que la conforman y frente a los órganos jurisdiccionales nacionales.

Está delimitado funcionalmente por la Convención Americana sobre Derechos Humanos y por los tratados internacionales sobre Derechos Humanos, sin límite alguno frente a la posición de un Estado, por cuanto dichos tratados no pueden tener una cláusula de exclusión por parte de un país para el seguimiento de un caso en su jurisdicción.

Está compuesto por dos entidades de carácter jurisdiccional, la Corte Interamericana de Derechos Humanos (Corte IDH) y la Comisión Interamericana de Derechos Humanos (CIDH).

\section{La Corte Interamericana de Derechos Humanos}

Tiene sede en la ciudad de San José de Costa Rica y está conformada por “jueces” designados por concurso público ante la OEA en representación de los países miembros. Tiene sede en Costa Rica porque en dicho país se celebró en 1969 la Conferencia Especializada Interamericana sobre Derechos Humanos, donde se firmó y suscribió la Convención Americana sobre Derechos Humanos (CADH), que entró en vigencia el 18 de julio de 1978, pues primero debía ser ratificada por once países de la región para que tuviera validez (Martín, 2004). A pesar de esta situación, solo hasta 1979 se pudo instalar la Corte IDH y, por petición de Costa Rica, la OEA decidió trasladar la sede a dicho país, situación que se institucionalizó el 3 de septiembre de 1979. 
La Corte IDH conoce los casos de violaciones de Derechos Humanos denunciados por un ciudadano miembro de un país que conforma la OEA cuando el derecho que se tutela está expresamente estipulado o deviene de la interpretación de la CIDH. Es importante señalar que, por un lado, para llegar a instancias de la Corte IDH es necesario que primero finalice la etapa jurisdiccional en cada país y, por el otro, que el denunciante no puede ingresar a dicho sistema si es una empresa o un ciudadano cuyos intereses se materializan en un ámbito comercial o empresarial, por cuanto este tiene un mecanismo jurisdiccional especial ante otra instancia.

Los casos que se llevan ente la Corte IDH tienen las siguientes características:

a. Se siguen bajo el formato de contradicción de partes: denunciante y Comisión Interamericana de Derechos Humanos y Estado agraviante, aun si este opone contradicción por competencia.

b. Se expide una decisión, cuya característica general es ser motivada, de carácter obligatorio y vinculante para las partes y con efectos inapelables al ser única e instancia final.

c. La decisión de la Corte IDH tiene además un carácter vinculante con el Estado a un nivel coercitivo, por cuanto puede operar mecanismos sancionatorios a nivel de la OEA sobre un país incumplidor.

d. La decisión de la Corte IDH tiene un carácter complementario, pues constituye doctrina jurisprudencial a nivel supranacional. En este sentido, es vinculante para los demás países cuando se lleven casos similares o de naturaleza equivalente.

e. Eventualmente, la Corte IDH puede tener una competencia consultiva cuando un país miembro de la OEA solicita una consulta a efectos de evaluar la naturaleza de una norma de carácter legal o constitucional frente a su adecuación a la Convención.

\section{La Comisión Interamericana de Derechos Humanos}

La CIDH es la entidad complementaria a la Corte IDH, con la cual se conforma el Sistema Interamericano de Protección de Derechos Humanos. Tiene sede en Washington debido a que en dicha ciudad se encuentran todas las sedes consulares y diplomáticas de todos los países en el mundo, a la vez que es sede de las Naciones Unidas. En esta ciudad, la capacidad operativa de la CIDH permite que todo Estado pueda ejecutar una defensa idónea en un plazo relativamente corto a efectos de limitar toda afectación de derechos a un ciudadano que alegue una violación de estos en su país. 
La CIDH está integrada por siete personas que, a diferencia de los jueces de la Corte IDH, son elegidas por sus condiciones profesionales y personales — no tanto por la designación de su propio país - con el fin de dotarlos de autonomía funcional frente a su país de origen en el caso de que se requiera (Brenes, 1992).

Es un órgano consultivo y a la vez de investigación de los casos que se siguen ante la Corte IDH, ante la cual actúa como entidad denunciante. De esta manera se genera una equivalencia entre las partes cuando se desarrolle un caso ante la Corte IDH, debido sobre todo a la limitación natural y funcional del ciudadano que ha denunciado la afectación a su derecho en su país de origen.

\section{Elementos referenciales sobre Derechos Humanos}

Por el carácter amplio y complejo que implica desarrollar este elemento conceptual, este trabajo se limita solo a los aspectos básicos, los cuales están vinculados sobre todo a la tutela normativa de los derechos de los ciudadanos frente a los Estados. Es decir, se materializa de alguna manera lo que el positivismo seńalaba frente al iusnaturalismo: la positivización de los derechos naturales como reconocimiento a las condiciones favorables a una persona que son preexistentes al Estado.

En el desarrollo de esta concepción se ha elaborado una serie de tratados internacionales que no solo la han protegido, sino que además la han formalizado en estructuras, las cuales se han denominado "generaciones" para efectos de analizar los alcances particulares de dichos derechos (Pérez, 2006).

Eventualmente, uno de los grandes problemas que existen para materializar los Derechos Humanos radica sobre todo en la oposición de determinados países a universalizar ese ámbito normativo, pero se trata más de una excepción que de la regla general.

Sin embargo, en este trabajo monográfico es importante desarrollar el concepto de Derechos Humanos debido al alcance procedimental y ejecutivo que tienen las disposiciones que establece la Corte IDH en sus decisiones, que no solo reconocen un derecho, sino que además los transportan a una esfera disponible para los ciudadanos, principalmente para que el Estado infractor pueda ejecutar una serie de acciones que materialicen el contenido tutelado del derecho.

De esta manera, se observa que existen "generaciones" de Derechos Humanos que, en esencia, complementan los conceptos sustantivos, elementos procedimentales y procesales. De esta manera, la decisión que toma la Corte IDH no solo contiene una disposición tuitiva, sino que además se puede ejecutar en una realidad nacional, inclusive si la normativa nacional dispone un procedimiento distinto, caso en el cual es reformado por la jurisdicción supranacional. 
Así, con base en las tres generaciones de Derechos Humanos que reconoce tradicionalmente la doctrina constitucional, es posible señalar:

a. La primera generación de Derechos Humanos hace énfasis en los derechos civiles y políticos de los ciudadanos, en particular para dotarlos de una autonomía frente al poder estatal, con lo cual limita toda situación que pudiere afectar sus derechos de naturaleza civil y política (Arévalo, 2001).

b. La segunda generación de Derechos Humanos desarrolla principalmente los derechos denominados "económicos, sociales y culturales" desde una perspectiva de desarrollo individual, pero con una incidencia social.

El reconocimiento de la condición social del individuo frente al Estado y frente a su propia comunidad es el elemento central en esta generación de Derechos Humanos, principalmente porque estos derechos son una progresión colectiva de aquellos derechos reconocidos como "individuales" (Morales, 1996).

El objetivo de este marco tuitivo de derechos es proteger sobre todo derechos que pueden ser "equiparados" a un colectivo determinado o determinable, partiendo de la defensa de derechos individuales. Derechos como la educación, el acceso al ámbito laboral, los derechos laborales, la negociación colectiva y los derechos culturales son un patrón característico de esta generación de normas.

c. Los derechos de tercera generación, reconocidos como "derechos difusos", tienen una especial característica: son derechos vinculados al ámbito de "pueblos", de manera que no se puede identificar específicamente a un colectivo en particular o a un individuo determinado.

Derechos como al "desarrollo", al "medio ambiente" o a la "paz" son los principales derechos reconocidos en esta generación de normas tuitivas, las cuales no cuentan con un marco normativo generalizado a través de un tratado internacional, sino que se desprenden de normas de carácter especial que cada país ha desarrollado en el ámbito de sus facultades ordinarias.

Los denominados "protocolos" que reconocen estos derechos no tienen un marco coercitivo para los países que conforman las Naciones Unidas, de manera que se complica judicializarlos con el fin de hacerlos viables y ejecutables en circunstancias de evaluación en caso de afectación por parte de un Estado. 
La explicación de este marco de desarrollo de "generaciones" resulta particularmente importante para este trabajo porque los derechos vulnerables y reconocidos por la Corte IDH se desarrollan siguiendo los alcances característicos de los derechos, sobre la base de su progresividad, de su inalienabilidad, de su carácter irrestricto y en función de su naturaleza humana.

Precisamente, este criterio justifica el concepto de las "reparaciones" que se analiza posteriormente, por cuanto se supera el concepto tradicional de un "marco reparatorio" en términos económicos y se alcanza inclusive situaciones de "compensación moral”. De esta manera, un Estado condenado por ejecutar acciones de afectación a los derechos de un ciudadano debe cumplir, bajo cargo de ser apercibido con sanciones internacionales a cargo de la Organización de los Estados Americanos.

\section{Elementos referenciales a la tutela de derechos fundamentales}

Los derechos fundamentales, como desarrollo de los Derechos Humanos, no solo otorgan facultades a las personas y un estatus jurídico en un ámbito de la existencia jurídica o normativa, sino que además tienen una significación objetiva (Blancas, 2007). Y respecto de esta significación objetiva son la conditio sine qua non del Estado constitucional democrático, ya que no pueden pensarse sin que exista el Estado constitucional contemporáneo. Con base en este principio se justifica la primera posición de este trabajo respecto a que solo en los Estados democráticos es viable la interpretación del principio de la dignidad de la persona humana.

Así, los derechos cumplen también funciones estructurales de gran importancia para los principios conformadores de la Constitución, porque legitiman al estado de derecho (Schneider, 1979, p. 23).

En términos conceptuales, los derechos fundamentales son aquellos derechos que se derivan de la naturaleza humana y que son el ámbito básico de las normas que todo Estado reconoce a favor del ciudadano para que este ejecute sus acciones y se desarrolle en el ámbito de su comunidad. Dichos derechos no admiten una limitación en forma subjetiva, aunque se pueden limitar siempre y cuando existan condiciones preexistentes en el ámbito normativo para ello, para lo cual la doctrina constitucional ha desarrollado una serie de esquemas de desarrollo en caso de conflicto.

En este sentido, los derechos fundamentales se pueden limitar solo en términos excepcionales y únicamente en un ámbito individual respecto de un 
ámbito especial. Así por ejemplo, el derecho "a la vida" se puede limitar si existe un conflicto entre los derechos de un feto (embrión en desarrollo) frente a los derechos de la madre. Igualmente, se puede mencionar el derecho a la propiedad frente al derecho del Estado a ejecutar un proceso de expropiación, siempre y cuando exista un carácter objetivo que lo faculte, como por ejemplo la satisfacción de un interés colectivo o superior y exista una necesidad pública. Finalmente, en el ámbito penal la libertad de tránsito puede ser restringida siempre y cuando exista una condena penal impuesta en un proceso penal, en la cual se hayan ejecutado todas las garantías procesales y constitucionales a favor del investigado y/o procesado por parte de los operadores jurisdiccionales que ejecutan una acción en representación del Estado.

Eventualmente, el conflicto entre derechos de igual jerarquía — como pueden ser los derechos fundamentales - se puede resolver sobre la base de diversos planteamientos teóricos, algunos de los cuales se presentan a continuación:

a. La teoría de la ponderación de derechos.

b. La teoría del balancing de derechos.

c. La teoría del objeto de la protección del contenido esencial de los derechos fundamentales.

En este contexto, es posible afirmar que la ejecución de "reparaciones" dispuestas por la Corte IDH a un Estado infractor no solo impondrá mecanismos sancionatorios, sino que también desarrollará un aspecto esencial en la tutela de los derechos de los ciudadanos: la tuición de los derechos, aun cuando existan causas que pudieran justificar una acción del Estado. En este sentido, si bien no se limita la acción estatal, sí se considera que esta debe adecuarse a un contexto previo y reglado para evitar la ejecución de acciones extralimitadas al ejercicio del ius imperium del Estado.

\section{La tutela de la dignidad humana en el ámbito jurisdiccional convencional}

Para comenzar este punto es necesario plantear una premisa fundamental que materializa el derecho constitucional en los ámbitos nacional, latinoamericano e internacional: la afirmación de que la dignidad de la persona y de los Derechos Humanos es el soporte del orden constitucional. Por esta razón se encuentra que la dignidad, regulada como principio constitucional, está presente en la redacción 
de las cartas fundamentales de los países con un régimen democrático, por cuanto la dignidad de la persona es el rasgo distintivo de los seres humanos respecto de los demás seres vivos, la que constituye a la persona como un fin en sí mismo, lo cual impide que sea considerada un instrumento o medio para otro fin.

Precisamente, este es el fundamento que desarrolla el artículo primero de la Constitución peruana, el cual constituye una norma pétrea por cuanto forma parte de la carta magna desde la reforma a la Constitución de 1933 y permaneció cuando entró en vigencia la Constitución de 1979 que la sustituyó. Además, el artículo $2 .^{\circ}$ reconoce que la dignidad como concepto dota al individuo con la capacidad de autodeterminación y le permite el libre desarrollo de la personalidad, de su personalidad.

Esta circunstancia es de especial interés para los alcances de este trabajo, pues las recientes decisiones de la Corte IDH han desarrollado el concepto de la reparación a la "dignidad afectada" del ciudadano cuando un Estado infractor ha violado sus derechos. Cabe señalar que la Corte no precisa una condición especial del ciudadano afectado frente a la acción arbitraria del Estado, pues a dicha instancia supranacional le basta la identificación de su afectación.

\section{La decisión de la Corte IDH}

Por disposición de la CIDH, los Estados parte que conforman la OEA se encuentran vinculados y supeditados a una jurisdicción de carácter supranacional, de alcance regional y que eventualmente tiene inclusive un carácter conminatorio en términos jurisdiccionales, con lo cual se refuerza su carácter superior, pero complementario al ámbito del desarrollo jurisdiccional que cada país dispone a favor de sus ciudadanos.

Dicho ámbito de coerción no implica que la Corte IDH ejecuta directamente sus disposiciones, ya que esta decisión se notifica al Estado infractor para que realice acciones que satisfagan el contenido material de la $\mathrm{CADH}$, la cual puede incluir la exigencia de modificar la redacción de la Constitución.

$\mathrm{Al}$ respecto, se puede mencionar el fallo de la Corte contra el Estado chileno en el caso de "La última tentación de Cristo" [Caso Olmedo Bustos y otros vs. Chile], en el cual dispuso que debía derogar las normas de carácter constitucional que estipulaban la posibilidad de una censura previa y de discriminación en función a una condición religiosa. Ante este fallo de la Corte IDH, Chile tuvo que modificar su Constitución y derogar en forma explícita la censura previa, lo cual evidencia que si una Constitución ha sido evaluada con las premisas que establece la $\mathrm{CADH}$, todas 
las normas de carácter nacional también pueden ser evaluadas y eventualmente derogadas por ser inconstitucionales. Finalmente, otro caso similar es la derogación de normas de carácter procesal penal que regulaban las acciones antiterroristas del Estado peruano a finales de la década de los años noventa del siglo pasado.

\section{El acceso a la jurisdicción de la Corte IDH}

La tutela de un derecho afectado o vulnerado por parte de alguna entidad o funcionario público implica necesariamente que todo ciudadano pueda recurrir, en uso de su derecho a la "acción" y "tutela jurisdiccional efectiva", a las instancias judiciales para cesar el acto violatorio o exigir una reparación a dicha acción.

Según la Constitución peruana, existen dos alternativas para la recurrencia a dicha situación: el poder judicial, que representa la jurisdicción ordinaria, y el Tribunal Constitucional, que representa la jurisdicción constitucional. Ambas instituciones jurisdiccionales tienen el poder y los mecanismos necesarios para intervenir en la tutela de derechos de algún ciudadano, si es que este denuncia un acto ejecutado por parte del Estado a través de alguna entidad pública o de funcionarios públicos, de tal manera que inclusive puede ejecutar acciones preventivas, represivas o cautelares. Sin embargo, ambas instituciones actúan en forma autónoma y no necesariamente en términos complementarios, por lo cual se suelen generan algunas situaciones confusas que eventualmente son dirimidas en el ámbito de la jurisdicción supranacional.

Por una parte, se acude al poder judicial cuando el trámite de la causa responde a circunstancias "ordinarias", de tal forma que se puede recurrir a la ejecución de tres instancias judiciales: juzgado especializado, Sala Superior-Apelaciones y Casación. En este escenario, se decide en términos directos y es factible que el propio poder judicial ejecute directamente sus fallos. De otra parte, se recurre a la instancia constitucional cuando el ciudadano alega la afectación de un derecho fundamental seguido en el trámite de un proceso judicial, de manera que el Tribunal Constitucional corrige el error procedimental en la vía ordinaria o eventualmente decreta la inconstitucionalidad de una norma, en caso de que la demanda contenga una acción que procure la adecuación normativa de las normas infralegales a los parámetros de la Constitución. En la eventualidad de que se haya recurrido a la vía constitucional por acción de defensa de un derecho (recurso de agravio), el Tribunal Constitucional corrige el error y reenvía el proceso a la vía ordinaria, donde se continúa con el trámite.

La única excepción que establece el Código Procesal Constitucional para acceder directamente al Tribunal Constitucional es cuando se procura la tutela inmediata de 
un derecho que, por su consideración, resulta imposible de defender eficazmente en el ámbito de un proceso ordinario. Sin embargo, actualmente esta situación es poco probable debido a las reglamentaciones que el Tribunal Constitucional ha dispuesto para el trámite de los recursos de agravio. En todo caso, el Tribunal Constitucional decide en última instancia y frente a su decisión solo corresponde acudir a la jurisdicción supranacional. En cambio, si el poder judicial decide, aun siendo la Corte Suprema, es posible acceder a la jurisdicción constitucional.

$\mathrm{Al}$ respecto, se puede mencionar el Caso Giuliana Llamoja Linares (Sentencia del Tribunal Constitucional n. ${ }^{\circ}$ 00728-2008-HC/TC), en el cual, a pesar del fallo de la Corte Suprema, el Tribunal Constitucional ejerció poder y evaluó no solo el fallo en Casación, sino también el procedimiento que se desarrolló en las instancias jurisdiccionales ordinarias inferiores, con el fin de hacer la valuación probatoria del caso. El argumento que sustentó el Tribunal Constitucional fue la tutela del derecho al debido proceso y a la falta de motivación argumentativa del caso.

Aunque este ejemplo evidencia que las decisiones del Tribunal Constitucional son la última y definitiva instancia en el ámbito nacional peruano, se puede recurrir a la jurisdicción supranacional en dos situaciones expresamente determinadas por la CADH:

a. Cuando existe una situación de gravedad extrema en la cual los derechos fundamentales de los ciudadanos requieran de un recurso de defensa inmediato por parte del Sistema Interamericano de Protección de Derechos Humanos, que en vía cautelar puede ejecutar una decisión que todo Estado debe cumplir.

Como ejemplo se puede mencionar el último recurso cautelar contra Perú en el Caso Conga (Ángeles \& Marcos, 2013, p. 35), donde se determinó que el Estado, al no afectar los derechos de la región de Cajamarca, podía continuar con las autorizaciones administrativas a favor de empresas mineras para generar actividades extractivas (CIDH, Medida Cautelar n. ${ }^{\circ} 2014$,11-452). Sin embargo, la medida cautelar sí se otorgó a favor de los líderes de la comunidad y se exigió al Estado que no ejecute ninguna acción limitativa o represiva contra sus derechos.

b. Cuando se ha cumplido la notificación del Tribunal Constitucional, el ciudadano que considere la violación de un derecho no tutelado en la vía ordinaria y constitucional tiene expedito la recurrencia a la jurisdicción supranacional.

Dado que la segunda situación es la más recurrente en Perú, en el siguiente apartado se analizan los casos que han sido presentados ante la Corte IDH. 


\section{Casos peruanos ante la Corte IDH y su incidencia en el ámbito de la tutela de derechos}

En términos procesales, hasta la fecha Perú es un referente como Estado infractor de los Derechos Humanos debido a las situaciones que tuvieron lugar durante el gobierno de Alberto Fujimori, quien fue acusado de ejecutar actos institucionales por parte del Estado en contra de los Derechos Humanos de los ciudadanos y de grupos de ciudadanos. El Estado peruano ha sido denunciado prácticamente por todo tipo de violaciones a los Derechos Humanos de nacionales y extranjeros con domicilio en el país, a tal punto que actualmente enfrenta más casos que países como Cuba, Argentina o Guatemala, donde se presume que existen situaciones que limitan los derechos fundamentales de sus ciudadanos, como ocurre en Cuba. Entre las jurisprudencias más importantes que la Corte IDH ha emitido contra Perú se encuentran:

a. La inconstitucionalidad de la legislación antiterrorista (Corte IDH, informe sobre legislación antiterrorista). Esta decisión generó la revisión de todas las decisiones condenatorias a terroristas que fueron impuestas cuando la jurisdicción especial contra estos delitos era la jurisdicción militar (Comisión Andina de Juristas, 1999, p. 113), en la cual operaba el juez "sin rostro" y no se daban las garantías procesales suficientes para garantizar un debido proceso.

Los casos de exceso de represión y hostigamiento contra terroristas, como sucedió con Mónica Feria y Atilio Cahuana, presuntos terroristas y agentes del narcotráfico, a quienes el Estado tuvo que indemnizar porque no encontró elementos objetivos que acreditaran su responsabilidad penal en los actos denunciados. Una situación similar se produjo con el caso de Lori Berenson (ciudadana americana), que denunció al Estado peruano por limitar sus derechos políticos en el país (Corte IDH, Caso Lori Berenson).

b. Caso Castro Castro, La Cantuta y Barrios Altos (Corte IDH, Caso Barrios Altos, Caso La Cantuta vs. Perú). Se trata de los casos más resaltantes e importantes de la Corte IDH en los países de la región, en particular porque se acreditaron "delitos de lesa humanidad", "responsabilidad objetiva de parte de los operadores estatales" y "la acreditación de la teoría del dominio del hecho" de agentes políticos sobre miembros de la Policía Nacional y Fuerzas Armadas para la ejecución de personas en situación de rendición o indefensión. 
c. La Corte IDH también encontró responsabilidad del Estado peruano en las violaciones a los derechos de ciudadanos extranjeros, casos Jaime Castillo Petruzzi (Corte IDH, Caso Castrillo Petruzzi y otros vs. Perú), Lautaro Mellado, Alejandro Astorga y María Pincheira. Estos ciudadanos chilenos fueron acusados de "traición a la patria" pese a que este tipo penal no corresponde a personas extranjeras, motivo por el cual se anuló sus sentencias penales iniciales.

d. Caso Cinco Pensionistas (Corte IDH, Caso Cinco Pensionistas vs. Perú), el cual permitió que en la región se considere la tutela de los derechos fundamentales de los jubilados y que incluso se estableciera una reforma procesal que permitió por primera vez la participación de las "víctimas" como partes procesales contra el Estado.

e. El caso de los 52 magistrados no ratificados vs. Perú (CIDH, Petición 33-03, 2006) eventualmente constituye el único caso en el cual se pudo haber producido una situación de imposición de modificación de la Constitución, por cuanto esta contiene un artículo inconstitucional que afecta la libertad de trabajo, la estabilidad laboral y la dignidad de los magistrados que deben ser sometidos a evaluación de ratificación si esta resulta negativa.

La petición de proceder a una conciliación antes de que fuera emitida una decisión evitó que Perú modificara su Constitución, de modo que el procedimiento de ratificación judicial se ha mantenido hasta la fecha, pero sujeta a mejores controles de legalidad, seguridad y debido proceso para las partes en evaluación.

Uno de los últimos casos que se siguen contra Perú en la Corte IDH es el de "Luis Antonio Galindo", abogado que alega vulneración de sus derechos a la libertad, al trabajo y al ejercicio de la abogacía, por cuanto ha sido acusado de ejecutar actos vinculados al terrorismo, específicamente, apología al terrorismo (Instituto de Democracia y Derechos Humanos PUCP, 2017). En esencia, la denuncia ante la CIDH radica en la criminalización del ejercicio de la abogacía, ejecutada a favor de grupos terroristas, la misma que a la fecha ha sido concedida a trámite.

\section{El desarrollo y ejecución de las decisiones de la Corte IDH}

Una vez la Corte IDH ha emitido una decisión ante un caso, el Estado infractor es notificado y se le especifica el tiempo en que debe proceder a la ejecu- 
ción de la decisión, el periodo en el cual debe proceder a remediar y reparar el daño provocado y eventualmente, si así lo indica, proceder a ejecutar las acciones de "reparación" moral que se hubieran indicado, las cuales van desde la modificación de la legislación denunciada o la ejecución de actos públicos de desagravio.

El caso del "ojo que llora" (La voz del Edén, 2017) es el más importante y representativo de esta situación. Se trata de un monumento que realizó un gobierno local en la ciudad de Lima a favor de las víctimas del terrorismo que hubiesen formado parte de las Fuerzas Armadas y la Policía Nacional. Al tomar en cuenta esta situación, la Corte IDH notificó al Estado peruano que debía incluir el nombre de presuntos terroristas en la nómina de presuntos agraviados por la acción de lucha contra el terrorismo, con objeto de reconocer que se les había afectado en sus derechos en forma desproporcional.

De esta manera, un monumento concebido a favor de quienes habían ofrendado su vida en la lucha contra el terrorismo, pasó a convertirse en un monumento a todos los caídos por la acción del terrorismo, tanto de parte de los grupos terroristas Sendero Luminoso y Movimiento Túpac Amaru, como también de parte de las Fuerzas Armadas. Esto no solo transformó su lógica inicial, sino que además planteó la cuestión de la jurisdicción de la Corte IDH sobre Perú, de tal manera que incluso se solicitó la inaplicación de dicho fallo, el cual fue retirado posteriormente.

\section{El análisis de las reparaciones impuestas por la Corte IDH}

Toda vez que se había señalado que las reparaciones impuestas al Estado infractor se producen en tres niveles, consideramos que actualmente las decisiones de la Corte IDH radican esencialmente en un patrón común y característico: la reparación del daño ocasionado no se limita a una cuestión patrimonial, sino que además eventualmente imponen un deber de comportamiento, como el ofrecimiento de disculpas públicas al Estado. De esta forma, la tutela de los Derechos Humanos adquiere otra perspectiva, superior al simple proceso de defensa de posiciones tanto en el vía jurisdiccional nacional como en la supranacional.

Desde esta perspectiva, se pueden identificar estos tres procedimientos en ejemplos sencillos que permiten asumir una posición general sobre la ejecución de una decisión de la jurisdicción supranacional en Perú, en este caso, de la Corte IDH:

a. Reparación económica a modo de indemnización. Es el procedimiento más común y referencial, limitado esencialmente a situaciones de determi- 
nación del quantum indemnizatorio, el cual se realiza en la moneda del país infractor.

b. Es importante tener presente que existe inclusive un procedimiento que determina el monto inicial de la indemnización, su liquidación y la liquidación de los intereses compensatorios, siendo el caso referencial el de Baruch Ivcher contra Perú (Corte IDH, Caso Baruch Ivcher vs. Perú).

c. Reparación moral, a modo de un pedido de disculpas expresas por parte del Estado infractor. Se ordena principalmente cuando se afecta a un grupo en especial respecto de los dańos provocados a los Derechos Humanos a grupos identificados como "víctimas". La disculpa pública por parte del Estado infractor se traduce más que todo como un acto que un Estado debe ejecutar en un ánimo de lograr la armonía social en su sociedad y pretende exclusivamente conseguir un clima armónico, a efectos de superar los problemas de violación de Derechos Humanos denunciados. La referencia más puntual de esta situación se produjo en Argentina con el caso Rodolfo Correa Belisle contra Argentina (Corte IDH, Caso Rodolfo Correa vs. Argentina).

d. El caso del "ojo que llora" contra Perú eventualmente no se considera propiamente un caso de disculpa pública, pero sí un acto de reconocimiento público de afectación a los Derechos Humanos a un grupo especial, en este caso a terroristas, sobre quienes se ejecutó una acción desproporcional por parte del Estado.

e. Reparación institucional. Esta puede consistir en la orden de modificar un sistema procesal respecto de un tema que involucró la recurrencia a la jurisdicción supranacional, situación que se representa en varios niveles. Por ejemplo, la Corte IDH solicitó la derogación de normas de carácter constitucional a un país cuando se registró la inconstitucionalidad de dichos alcances y le exigió un periodo de tiempo prudencial para dicha modificación. El caso representativo fue "La tentación de Cristo" contra Chile, respecto de la regulación constitucional de la censura y la libertad de expresión regulados a favor del Estado (Corte IDH, Caso Olmedo Bustos y otros vs. Chile o "La última tentación de Cristo").

f. Para el caso peruano, el mejor ejemplo de esta situación es la derogación de la legislación antiterrorista del gobierno de Alberto Fujimori, la cual establecía la facultad de la jurisdicción penal militar sobre actos de terrorismo. 


\section{Conflicto de intereses}

Los autores declaran que no existe ningún potencial conflicto de interés relacionado con este capítulo.

\section{Financiación}

Los autores no declaran fuente de financiamiento para la realización de este capítulo.

\section{Referencias}

Ángeles Fernández, M., \& Marcos, J. (2013). Diez encuentros incómodos con América del Sur. CRAC. Arévalo Álvarez, L. (2001). El concepto jurídico y la génesis de los Derechos Humanos. Universidad de Puebla.

Blancas Bustamante, C. (2007). Derechos fundamentales de la persona y relación de trabajo. PUCP.

Brenes Rosales, R. (1992). Introducción a los Derechos Humanos. Editorial Universidad Estatal.

Comisión Andina de Juristas. (1999). Protección de Derechos Humanos. CAJ.

Comisión Interamericana de Derechos Humanos [CIDH]. (2006, octubre 21). Caso de los magistrados no ratificados vs. Perú. Petición 33-03 y otras, Solución Amistosa. http://www.cidh.oas. org/annualrep/2006sp/Per\%FA33.03sp.htm

Comisión Interamericana de Derechos Humanos [CIDH]. (2014, mayo 5). Medida Cautelar N. ${ }^{\circ}$ 11-452, Líderes y lideresas de Comunidades Campesinas y Rondas Campesinas de Cajamarca respecto de la República de Perú. https://www.oas.org/es/cidh/decisiones/pdf/2014/mc-452 -11es.pdf

Corte Interamericana de Derechos Humanos [Corte IDH]. (mayo 30, 1999). Castillo Petruzzi y otros vs. Perú. www.corteidh.or.cr/docs/casos/articulos/seriec_52_esp.pdf

Corte Interamericana de Derechos Humanos [Corte IDH]. (2001, febrero 5). Caso Olmedo Bustos y otros vs. Chile o la Última Tentación de Cristo contra Chile. www.corteidh.or.cr/docs/casos/ articulos/seriec_73_esp.pdf

Corte Interamericana de Derechos Humanos [Corte IDH]. (2001, febrero 6). Caso Baruch Ivcher vs. Perú. www.cidh.oas.org/relatoria/showDocument.asp?DocumentID=44

Corte Interamericana de Derechos Humanos [Corte IDH]. (2004, noviembre 25). Caso Lori Berenson vs. Perú. http://www.corteidh.or.cr/docs/casos/articulos/seriec_119_esp.pdf

Corte Interamericana de Derechos Humanos [Corte IDH]. (2010, marzo 16). Caso Rodolfo Correa Belisle vs. Argentina. https://www.cidh.oas.org/annualrep/2010sp/ARSA11758ES.doc

Corte Interamericana de Derechos Humanos [Corte IDH]. (2010, noviembre 1). Informe sobre la legislación antiterrorista por la CIDH. https://www.google.com.pe/url?sa=t\&rct=j\&$\mathrm{q}=\&$ esrc $=$ \&\&source=web\&cd $=10 \&$ ved $=0$ CGEQFjAJ \&url=http\%3A\%2F\%2Fwww.cidh.oas. org\%2Fannualrep\%2F2010sp\%2F69.PEAD755-04ES.doc\&ei=8A6qU4yDY2Jqgb1zoKwB- 
g\&usg=AFQjCNEMDrTjnR8y8ryK1CRSkHTN4ah19A\&sig2=52RwRDhqBGeUUG_ mQIrKcg

Corte Interamericana de Derechos Humanos [Corte IDH]. (2013, febrero 28). Caso Cinco Pensionistas vs. Perú. www.corteidh.or.cr/docs/casos/articulos/Seriec_98_esp.doc

Corte Interamericana de Derechos Humanos [Corte IDH]. (2001, marzo 14). Casos Barrios Altos y La Cantuta. http://www.corteidh.or.cr/docs/casos/articulos/Seriec_75_esp.pdf

Instituto de Democracia y Derechos Humanos PUCP. (2017). Nuevo caso peruano ante la CIDH. Criminalización del ejercicio de la abogacía. http://idehpucp.pucp.edu.pe/comunicaciones/ opinion/nuevo-caso-peruano-ante-la-corte-interamericana-criminalizacion-del-ejercicio-de-la-abogacial

Martín, C. (2004). Derecho Internacional de los Derechos Humanos. Universidad Iberoamericana.

Morales Gil, H. (1996). Derechos Humanos: dignidad y conflicto. Universidad Iberoamericana.

Pérez Luño, A. (2006). La tercera generación de Derechos Humanos. Aranzandi.

Schneider, H. P. (1979). Peculiaridad y función de los derechos fundamentales de un Estado constitucional democrático. Revista de Estudios Políticos [Nueva época], 7, 7-35.

La Voz del Edén. (2017). El ojo que llora. http://blog.pucp.edu.pe/item/10272/el-ojo-que-llora-likamutal 